\title{
Oceanography
}

CITATION

Kappel, E.S. 2013. Quarterdeck: More electronic formats of Oceanography available soon.

Oceanography 26(1):5, http://dx.doi.org/10.5670/oceanog.2013.09.

$\mathrm{DOI}$

http://dx.doi.org/10.5670/oceanog.2013.09

COPYRIGHT

This article has been published in Oceanography, Volume 26, Number 1, a quarterly journal of The Oceanography Society. Copyright 2013 by The Oceanography Society. All rights reserved.

USAGE

Permission is granted to copy this article for use in teaching and research. Republication, systematic reproduction, or collective redistribution of any portion of this article by photocopy machine, reposting, or other means is permitted only with the approval of The Oceanography Society. Send all correspondence to: info@tos.org or The Oceanography Society, PO Box 1931, Rockville, MD 20849-1931, USA. 


\section{More Electronic Formats of Oceanography Available Soon}

\author{
P.O. Box 1931 \\ Rockville, MD 20849-1931 USA \\ t: (1) 301-251-7708; f: (1) 301-251-7709 \\ www.tos.org
}

The Oceanography Society was founded in 1988 to disseminate knowledge of oceanography and its application through research and education, to promote communication among oceanographers, and to provide a constituency for consensus-building across all the disciplines of the field.

OFFICERS

Mark Abbott, President Susan Lozier, President-Elect Mike Roman, Past-President Susan Cook, Secretary

Susan Banahan, Treasurer

\section{COUNCILLORS}

$\begin{array}{cc}\text { Amy Burgess } & \text { Blanche Meeson } \\ \text { Scott Glenn } & \text { Mary Scranton } \\ \text { Steven Lohrenz } & \text { Janet Sprintall } \\ \text { Gail Kineke } & \text { Deborah Steinberg }\end{array}$

\section{EXECUTIVE DIRECTOR} Jennifer Ramarui

SPONSORS

Lockheed Martin Sippican Inc. www.sippican.com

Ober | Kaler www.ober.com

Satlantic

www.satlantic.com

Sea-Bird Electronics Inc. www.seabird.com

Teledyne RD Instruments www.rdinstruments.com

WET Labs www.wetlabs.com
The Oceanography Society continues to add electronic viewing options for Oceanography to make the magazine more broadly accessible. We started by introducing a full electronic version through Qmags (http://www.qmags.com) in fall 2012 that could be viewed either with a Web browser or by downloading a PDF. With the December 2012 issue, we introduced an iPad version. TOS members can go to the Apple App Store and download the Oceanography app, which will give them access to the magazine. Nonmembers can also download the app, but they must purchase the available issues by following links to Qmags.

We are very pleased to announce that users who prefer Android or Kindle platforms will very soon be able to go to the Google Play site for the Android app or to the Amazon Kindle Store to download the new Oceanography apps. As with the iPad version, from the app welcome page, you will be asked to enter your user ID and password. It is the same login information that you use to access the other electronic versions of Oceanography. This login information was provided via e-mail to all active TOS members on 12/18/2012 from Qmags (distribution@qmags.com). The user ID is the e-mail address on file with TOS, and the password was generated by Qmags. There is a password recovery tool on the welcome page in case you cannot find your login information. Contact Jenny (jenny@tos.org) if you are having difficulties. After successfully logging in, issues of Oceanography will appear in your library. Click on the cover of the desired issues to download them to your desired electronic platform.

With more electronic options available, we expect that some members may not wish to receive paper copies of Oceanography any longer. If that is the case, please e-mail Jenny at jenny@tos.org.

Finally, if you find a bug or can suggest some improvements to any of these apps, please let us know. You can expect updates to them roughly every few months, and we hope to be able to incorporate user comments in them.

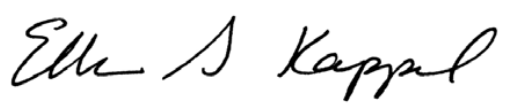

ELLEN S. KAPPEL, EDITOR 